\title{
Autonomous and portable radioactivity mapping system for environmental survey (SOCRATE)
}

\author{
P. Richon \\ Institut de Protection et de Sûreté Nucléaire, DPRE/SERGD, \\ BP. 6, 92265 Fontenay-aux-Roses, France
}

\begin{abstract}
SOCRATE is a cartographic tool for natural and artificial radioactivity survey, developed for implementation in contaminated sites and natural environments. The comprehensive mapping of a contaminated surface ( 10.000 square meters, with a grid as small as one meter across) is possible in one day by two surveyors only. The system uses a differential GPS (DGPS Novatel ${ }^{\mathrm{TM}}$ ) and a gamma probe (Saphymo ${ }^{\mathrm{TM}}$ AD6128), making it possible to obtain in real time the dose rate and the geographical position (latitude, longitude and elevation) with an accuracy of 0.2 meter. It is made up of two distinct parts: the sensor and its ancillary equipment, including GPS, packed in a rucksack $(10 \mathrm{~kg})$, and the reference GPS station located on a tripod in the site. The GPS receivers are radio-linked (range $12 \mathrm{~km}$ ) in order to make differential corrections available in real time at the mobile station. The mobile station is equipped with a computer and a LCD screen, allowing the simultaneous visualization of path and dose rate. The data file includes geographical position, elevation, and dose-rate in nSv. ${ }^{-1}$. These parameters are directly processed by ARCVIEW ${ }^{T M}$ (a Geographical Information System), which produces dose rate contours. These maps can be superimposed to topographic maps, aerial photographs or digital terrain modelling. The SOCRATE system has already been implemented on several sites, including Saint-Jean d'Ormont (Vosges), the Mercantour natural park (Alpes Maritimes), and the village of Gif-sur-Yvette (Essonne).
\end{abstract}

\section{BACKGROUND}

Using conventional techniques the creation of radiological maps of a ground surface of around $10,000 \mathrm{~m}^{2}$ requires a surveyor to create the "grid" (cross-sectioning in squares) and some ten operators for more than a week to measure and input each value measured over a $1 \mathrm{~m} \times 1 \mathrm{~m}$ meshwork. The processing of this data requires extensive set up work. The resulting delay between the measurement and the creation of the map does not allow for rapid response to the authority requesting the analysis. The SOCRATE programme was developed precisely to reduce this delay whilst increasing the speed and accuracy of the data and by reducing the cost of the analysis.

\section{DESCRIPTION}

SOCRATE is based on the GPS (Global Positioning System) that gives rapid location (in longitude, latitude and altitude) of all points of the globe using a group of satellites. The standard version GPS, as used by navigators, has an accuracy of around 10 meters, which is insufficient for the planned application: certain radioactive traces in effect have a surface of less than a one square meter, which would not be detected using this level of resolution. It is for this reason that the DGPS (Differential Global Positioning System) option has been called upon that uses two stations linked by radio: one fixed reference station installed on the site and a mobile station carried by the operator. This device enables in real time a location to be obtained to within 0.2 meters. The mobile station is incorporated into a rucksack (fig.2) and comprises a total gamma ray dose rate detection sensor (MPP2 6150 AD, Saphymo) positioned at $0.5 \mathrm{~m}$ from the ground, the GPS receiver, the radio connection system to the fixed station (fig.l), the computer controlling the acquisition, a screen to display the range and dose rate and finally an electrical supply giving 2 hours' independent operation (fig.3). The assembly weighs less than 10 kilos. 


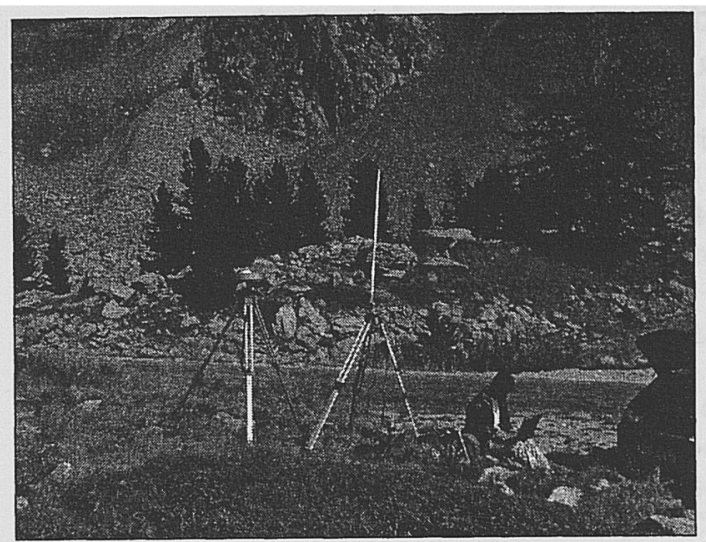

Figure 1: The fixed station installed on the site (Mercantour).

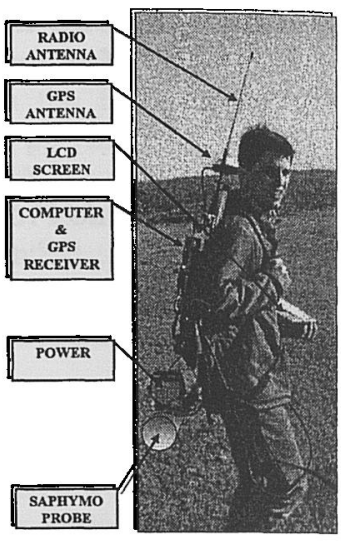

Figure 2: The mobile station Packed in a rucksack.

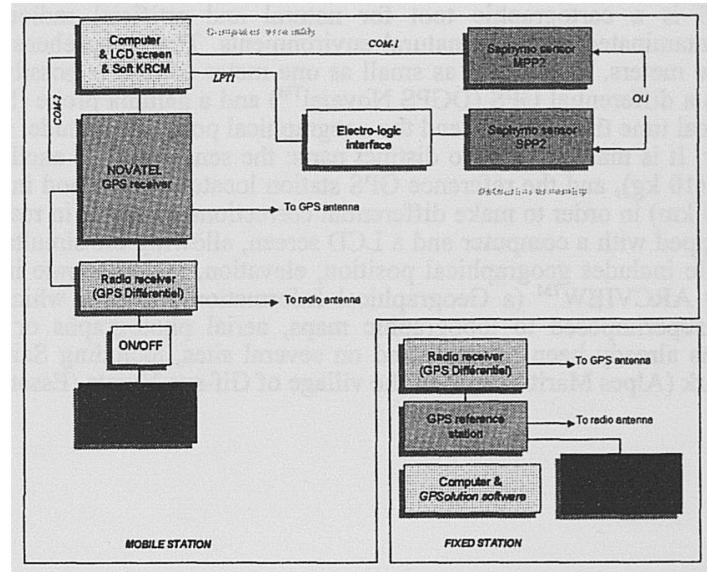

Figure 3: SOCRATE system flowchart diagram.

\section{FIELDS OF APPLICATION}

Its compact size and ease of use enables SOCRATE to map all types of terrain, even rugged relief terrain. Currently, two operators carry out the acquisition of data over a $10,000 \mathrm{~m}^{2}$ site using a meshwork of one meter during one day of measurement. For larger surfaces it is possible to adapt the system onto a vehicle. The main advantage of SOCRATE is in the possibility of going back over the terrain, in repositioning exactly over the same mark, to map the site again and to be able to compare the results, for example following decontamination operations.

\section{STUDY AREAS}

SOCRATE has been used in several measurement campaigns over varied topographical terrain like the contaminated site of Saint-Aubin in the Essonne (during the test phase of the prototype), a site for storing the mineral residue of uranium (for determination of the radiological homogeneity of covering materials), a terrain situated at Gif-sur-Yvette (map 1) showing traces of radium contamination and finally the sites affected by the fall-outs of Chernobyl, St Jean d'Ormont (Vosges) and Mercantour (map 2). On this latter site, the results are comparable to those previously obtained by SERNAT using the conventional methods, which enabled the tool to be validated. 


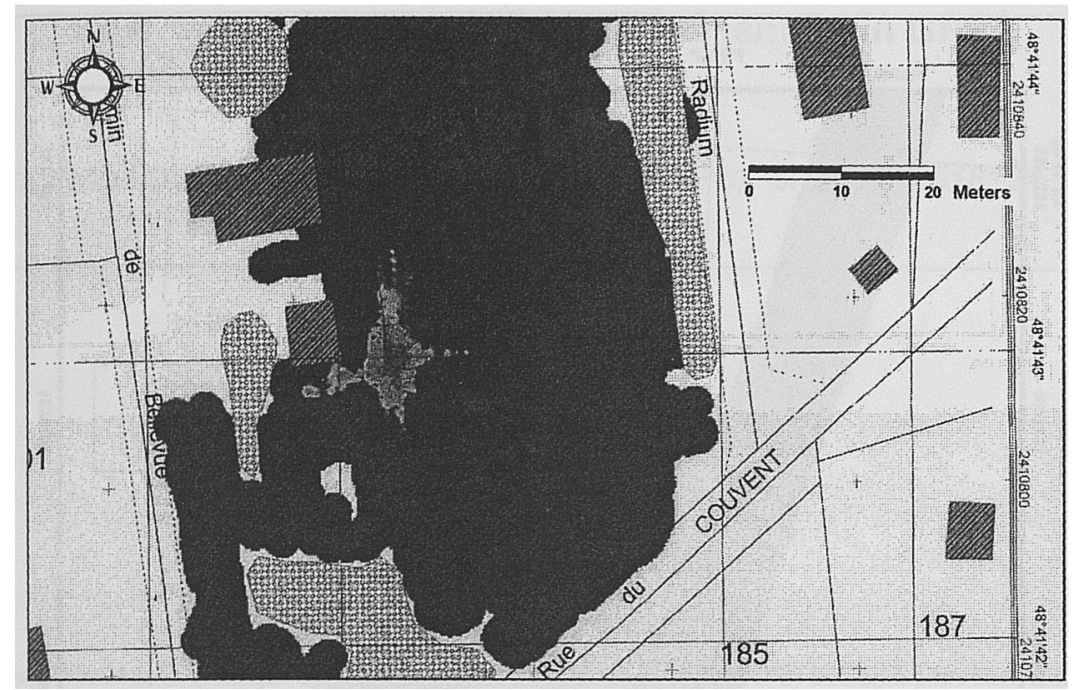

Map 1: Measured dose rate over Gif-sur-Yvette site (Black surface $70 \mathrm{nSv} \cdot \mathrm{h}^{-1}$, and grey surface $4000 \mathrm{nSv} \cdot \mathrm{h}^{-1}$ ). .

\section{CO-OPERATION-PERSPECTIVES}

With regard to navigation: the GPS system does not operate beneath a cover of vegetation or in a very enclosed site. It must "see" a minimum of 5 satellites to reach the required level of precision. This is why it is planned to add a gyro-compass (bearing measurement) linked to an odometer (measurement of the distance travelled) in order to relay the GPS when the GPS "disconnects". This method has already been used with success in the navigation system of the LEIRPA radon measurement mobile laboratory.

With regard to detection: for the moment, the only range measured (and reported on the maps) is the total gamma dose rate, without identification of the radionuclides responsible for the signal. One of our next objectives is to perform this identification using a portable spectrometer capable of discriminating the energy from the gamma photons emitted via each point of measurement, all remaining within a reasonable system weight limit.

\section{References}

Pourcelot L., Marquet J., Leprieur F., Rapport Scientifique annuel 2000. Contamination des bassins versants d'altitude suite à l'accident de Tchernobyl : Exemple du Massif du Mercantour. Rapport DPRE/SERNAT 2001-12.

Richon P., SOCRATE, Système d'observation et de cartographie de la radioactivité autonome et transportable pour 1'environnement (Version 1). Rapport DPRE/SERGD 00-49, octobre 2000. 


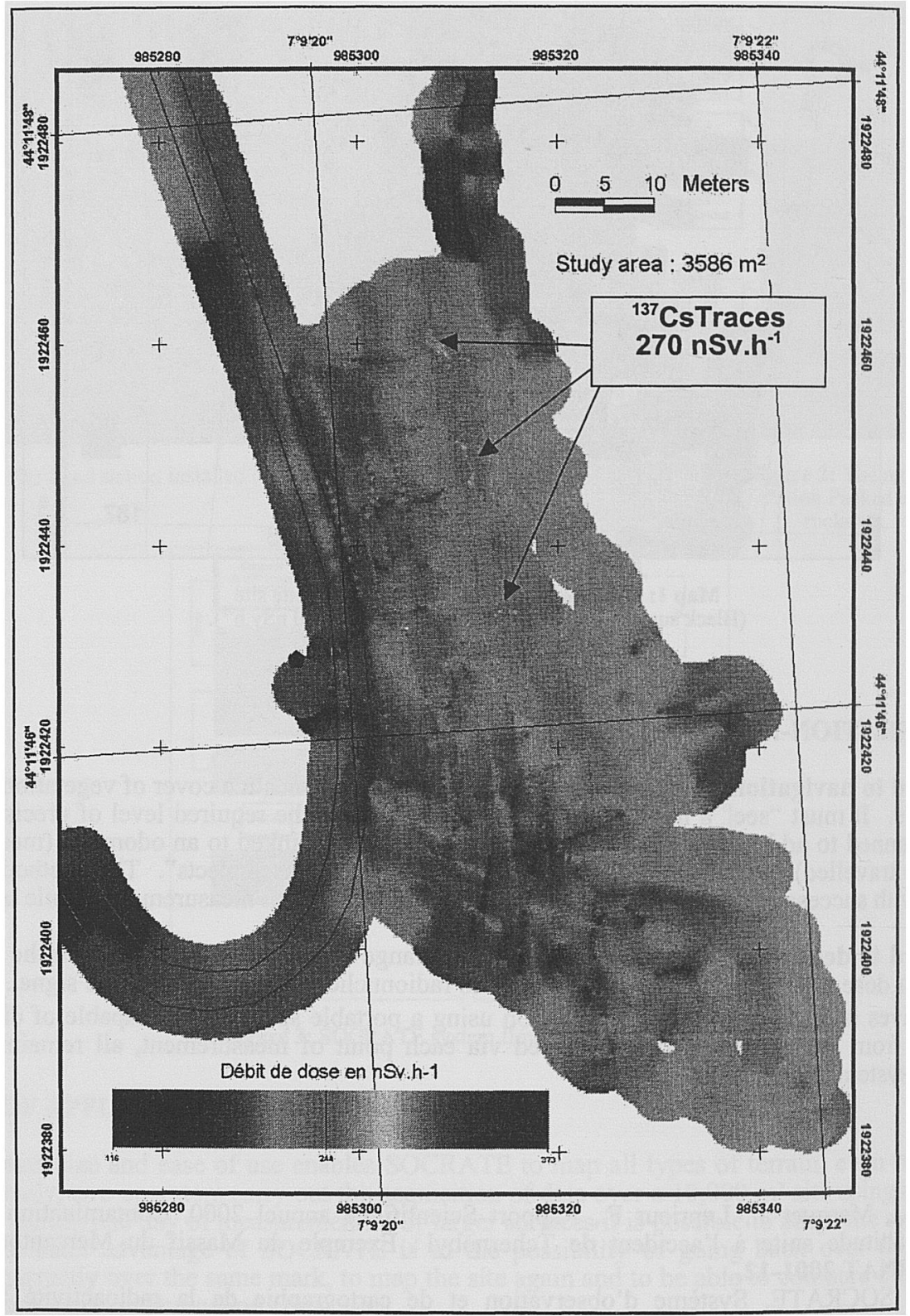

Map 2: Measured dose rate over the workshop zone studied by SERNAT (Mercantour) indicating traces of contamination via the ${ }^{37} \mathrm{Cs}$ from the fall-outs from the Chernobyl accident. 